\title{
Numerical study of a marine dual-fuel four-stroke engine
}

\author{
G. Theotokatos, S. Stoumpos, \& I. Lazakis \\ University of Strathclyde, Glasgow, UK \\ G. Livanos \\ Technological Educational Institute of Athens, Egaleo, Greece
}

\begin{abstract}
Continuously increasing environmental demands in conjunction with the planned strong penetration of the LNG, render the use of LNG as an attractive alternative marine fuel. In this framework, the traditional ship propulsion plants based on Diesel engines running with HFO, should be revisited and compared to the more efficient and environmentally friendly propulsion systems that use dual fuel engines. The present study deals with the computational investigation of a marine four-stroke dual fuel (DF) engine, in both diesel and DF mode operation. The engine model was set up in a commercial software and used to compare the performance and emissions of the investigated engine operation at steady state conditions. The engine diesel mode was initially set up and the model was calibrated to adequately represent the engine operation. Subsequently, the engine dual fuel model was set up by considering the injection of two different fuels; methane and pilot diesel fuel. The derived results were analysed for revealing the differences of the engine performance and emissions at each engine mode. In addition, the turbocharger matching at each mode is investigated revealing the challenges due to the completely different air-fuel ratio strategies used in diesel and dual fuel modes, respectively.
\end{abstract}

\section{INTRODUCTION}

Gaseous emissions from marine diesel engines, i.e. NOx, SOx, PM, HC, $\mathrm{CO}$ and $\mathrm{CO}_{2}$, have been steadily increasing throughout the last years. It is estimated that shipping accounts for $2-3 \%$ of global emissions (Bows-Larkin et al., 2014). In order to control these emissions and eliminate air pollution, various regulatory bodies such as IMO (IMO, 2014a) (IMO, 2014b), EMSA (EMSA, 2015) and EPA (EPA, 2015) have adopted a series of regulations. The International Maritime Organisation (IMO) and various national authorities introduced legislation for limiting non-greenhouse gaseous emissions including NOx and SOx, as well as the greenhouse gaseous emissions; mainly $\mathrm{CO}_{2}$. These amendments of the international legislation introduced the Energy Efficiency Design Index (EEDI) as well as the Ship Energy Efficiency Management Plan (SEEMP) that can be based on the Energy Efficiency Operational Indicator (EEOI). The expected benefits from the implementation of the above include not only the reduction of the environmental impact of gaseous emissions, but also the reduction of the fuel consumption throughout the ship lifetime leading to minimised operating costs that affect the competitiveness of the shipping companies (Theotokatos \& Tzelepis, 2015).
Due to these regulatory limitations that have arisen throughout the last years, the engine manufacturers e.g. (MAN, 2012) and (Wärtsilä, 2015a), as well as Classification societies e.g. (ABS, 2013) have performed studies focusing on the emissions reduction. In addition, the engine manufacturers accomplished efforts to improve the combustion characteristics, so that to maximise the engine efficiency, thus reducing fuel consumption, as well as to reduce the engines gaseous emissions. Marine engine manufacturers have also developed dual fuel (DF) versions both for large two stoke slow speed engines and small to medium size, four-stroke engines. These engines can run on dual fuel and diesel modes; in the former mode by using natural gas and pilot diesel fuel, in the latter mode by burning diesel fuel (HFO or $\mathrm{MGO}$ ).

Natural gas (NG) is the greenest fossil fuel that is a proven and available solution (Livanos et al., 2014). Whilst the conventional diesel fuels will remain the main option for the majority of the existing vessels in the near future, the commercial opportunities of the natural gas are attractive for new-built vessels. The sulphur content of natural gas is almost zero (about $0.004 \%$ by mass to mass basis), which is well below the $0.1 \%$ sulphur required in ECAs from 2015 , and as a result the SOx emissions of the engines operating in DF mode are very low ( $\mathrm{SOx}$ 
emissions can be reduced up to $90-95 \%$ compared with the diesel mode operation at HFO). In addition, the DF engines can achieve up to $85 \%$ NOx emissions reduction (as they operate in the lean burn combustion concept), the $\mathrm{CO}_{2}$ emissions can decrease up to $20-25 \%$ (due to the natural gas lower carbon to hydrogen ratio), whereas the particulate matter (PM) emissions are almost eliminated and there is no visible smoke during engine operation at DF mode. Furthermore, the price of LNG is also attractive; about $60 \%$ of the HFO price (Wärtsilä, 2012) (Livanos et al., 2014), although the market is volatile and the fuels prices are affected by various parameters including geopolitical factors. Fourstroke DF engines operate at low gas pressure (5-7 bar) with a typical brake mean effective pressure (BMEP) at around 25 bar. There are two types of two stroke DF engines; one operating at high fuel gas pressure (around 300 bar) in which the gas is injected during the combustion phase (MAN, 2015); the other operating in low fuel gas pressure (around 7 bar) in which the gas is injected into the engine cylinder during the compression phase (Ott, 2015).

Previous research on dual fuel engines are reported in detail in Karim (2015). Past research efforts dealt with increasing the DF engines efficiency, optimising the pilot fuel injection and gas substitution rate, extending the operating range of DF mode and avoiding knocking as described in Xu et al. (2014). Simulation tools of various complexities (0D to 3D ) (Merker et al., 2006) have been extensively used for investigating the DF engine steady state performance and transient response (Xu et al., 2014) as well as for analysing marine engines and ship propulsion systems (Benvenuto et al., 2013), (Theotokatos \& Tzelepis, 2015), (Baldi et al., 2015).

The main objective of the present study is to develop and use a model capable of simulating a marine dual-fuel engine. Based on this, the investigation of the engine steady state performance and exhaust emissions is carried out at the engine discrete operating modes (diesel/dual fuel). By analysing the derived results, the processes that affect the engine efficiency and gaseous emissions are revealed enabling the elaboration on possible ways to increase the engine efficiency and reduce emissions. In addition, the turbocharger matching is discussed as different requirements are imposed in each operating mode.

\section{ENGINE MODELLING}

\subsection{Investigated engine}

The Wärtsilä engine W9L50DF was used for the present study, which is a four-stroke, non-reversible, turbocharged and intercooled DF engine. The engine consists of nine cylinders placed in-line. This type of engine is widely used due to its high power output along with its fuel flexibility, low emission rates, high efficiency and reliability. The engine details are reported in the manufacturer project guide (Wärtsilä, 2014). The main engine characteristics are illustrated in Table 1. The engine operation at constant speed of $514 \mathrm{rpm}$ was investigated in the present study. Engine operation under these conditions can be found in electric propulsion systems, where engine-electric generator sets are used for producing the ship required electric energy.

Table 1. Engine main characteristics.

\begin{tabular}{lll}
\hline MCR power & $\mathrm{kW}$ & 8775 \\
MCR speed & $\mathrm{rpm}$ & 514 \\
BMEP at MCR & $\mathrm{bar}$ & 20 \\
BSFC at MCR (Diesel mode) & $\mathrm{g} / \mathrm{kWh}$ & 190 \\
BSEC at MCR (DF mode) & $\mathrm{kJ} / \mathrm{kWh}$ & 7300 \\
Bore & $\mathrm{mm}$ & 500 \\
Stroke & $\mathrm{mm}$ & 580 \\
No. of cylinders & - & 9 \\
Turbocharger units & - & 1
\end{tabular}

MCR: maximum continuous rating; BMEP: brake mean effective pressure; BSFC; brake specific fuel consumption; BSEC: brake specific energy consumption.

\subsection{Model set-up and calibration}

The software used in the present work is GTPower (Gamma Technologies, 2015), which is a widely used 1D simulation program for engine modelling and analysis. The data required for the modelling stage as input was acquired from the product guide (Wärtsilä, 2014) and the engine 3D model (Wärtsilä, 2015b). Initially, the model for one cylinder block was developed and validated for the diesel mode operation and subsequently, the model was extended to cover the dual fuel operation by adding an additional injector for the natural gas connecter to the cylinder intake port (upstream the intake valve). Then the whole engine model including the turbocharger and air cooler (shown in Figure 1) was developed.

The steps required to set up the engine model are as follows. Initially, the component blocks are selected, which sufficiently represent the engine layout and the appropriate interconnections are established. Then, the input data of all blocks are set. Preliminary calibration of the model constants is performed for a reference point and simulation runs are carried out. Finally, the fine tuning of the model constants is accomplished, so that the required accuracy is obtained.

The following input data are needed to set up the model: the engine geometric data, the intake and exhaust valves profiles, the compressor and turbine performance maps, the waste gate geometric and control details, the constants of engine sub-models (combustion, heat transfer and friction), the engine operating point (load/speed) and the ambient conditions. Initial conditions are required for the tempera- 
ture, pressure and composition of the working medium contained in the engine cylinders, pipes and receivers.

The Woschni heat transfer model (Woschni, 1967) was used to calculate the in-cylinder gas to wall heat transfer coefficient. The heat release rate was simulated according to single Vibe model (Merker et al., 2006) for the engine diesel operating mode, whilst in the case of the DF mode, the multi-Vibe model was utilised by imposing two different Vibe curves representing the pilot diesel fuel and gas fuel (methane) combustion, respectively. Therefore, the combustion heat release for the DF mode is calculated according to the following equation:

$$
\begin{aligned}
\dot{Q}_{c}=b_{D}( & \left.1-e^{-a \cdot \tau_{D}^{m_{D}+1}}\right) m f_{D} h_{D} \\
& +b_{N}\left(1-e^{-a \cdot \tau_{N}^{m_{N}+1}}\right) m f_{N} h_{N}
\end{aligned}
$$

In eq. (1), $b_{D}$ and $b_{N}$ denote the fraction factors for the pilot diesel fuel and natural gas, the sum of which should be equal to $1 ; \alpha$ is the Vibe functions parameter considered to be 6.9 for both pilot diesel and natural gas; $m_{D}, m_{N}$ are the Vibe shape factors of the considered Vibe curves; $\mathrm{mf}_{\mathrm{D}}$ and $\mathrm{mf}_{\mathrm{N}}$ denote the injected fuel amount per cycle and cylinder for the pilot diesel fuel and natural gas, respectively; $h_{D}$ and $h_{N}$ represent the effective combustion heat for the pilot diesel fuel and natural gas, respectively. The normalised time $(\tau)$ is calculated by using the following equation as function of start of combustion for each fuel $\left(\mathrm{SOC}_{\mathrm{D}}, \mathrm{SOC}_{\mathrm{N}}\right)$, each fuel combustion duration $\left(\Delta \theta_{\mathrm{D}}, \Delta \theta_{\mathrm{N}}\right)$ and the crank angle $(\mathrm{CA})$ :

$$
\tau_{D}=\frac{\mathrm{CA}-S O C_{D}}{\Delta \theta_{D}} \text { and } \tau_{N}=\frac{\mathrm{CA}-\mathrm{SOC}_{N}}{\Delta \theta_{N}}
$$

For the simulation of the diesel mode operation, MGO was used as the model fuel type along with the injection timing and injected fuel amount; both were provided as function of the engine load. For the DF mode, the amount of injected gaseous fuel per cycle (NG) was calculated by considering the known gas specific energy consumption and the fuel lower heating value. The gas fuel is injected at each cylinder intake port (upstream the inlet valves). The gas injection duration for each injector was considered to be 30 degrees $\mathrm{CA}$ and the injection takes place during the respective cylinder induction process after the exhaust valve closing point, so that all the injected gas is inducted into the engine cylinders. The engine valves timing was according to the Miller timing; the intake valves of each cylinder close before bottom dead centre (BDC).

Finally, the complete engine model with the intercooler and the turbocharger was built for the diesel and DF modes. For this, a waste gate valve was also used to bypass the exhaust gas by the turbocharger turbine. For the DF engine operation, the waste gate opening is controlled by engine boost pressure and as a result the engine cylinders air flow rate is adjusted to obtain the required air-fuel equivalence ratio window (values between 2.0 and 2.2 are accepted). This allows a smooth combustion of the natural gas avoiding knocking issues. The developed model layout is presented in Figure 1.

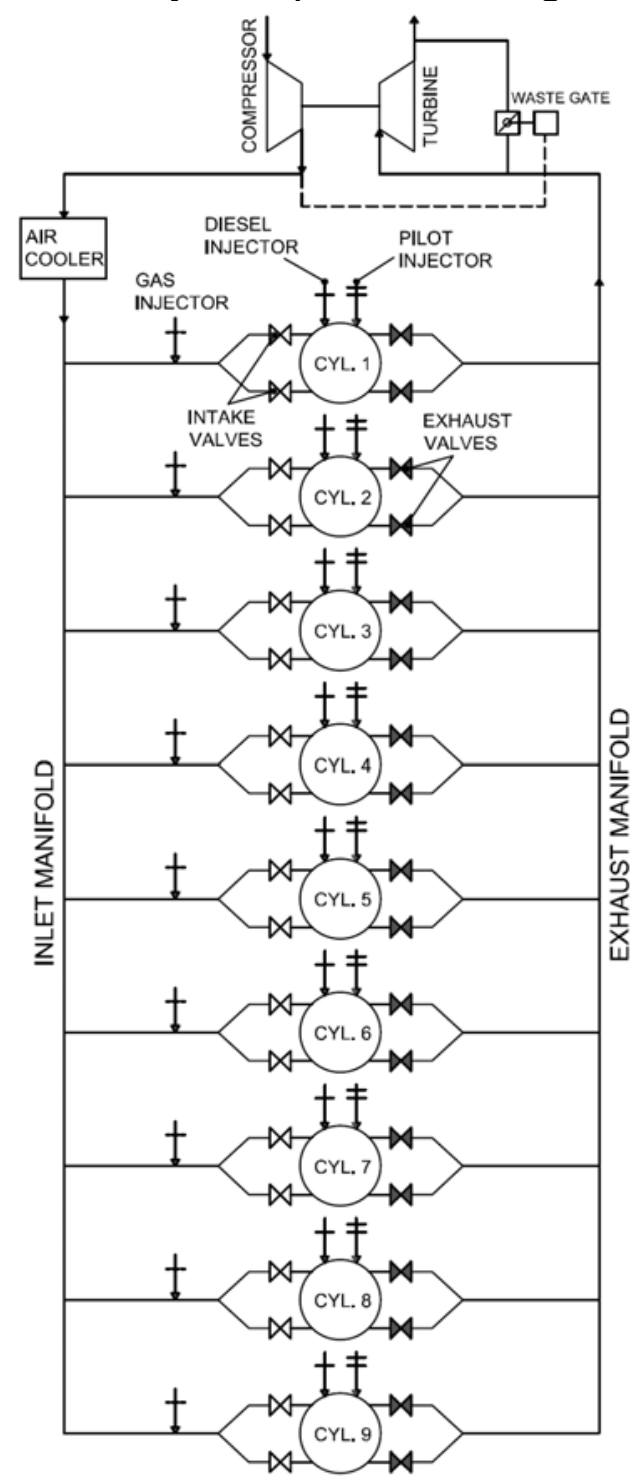

Figure 1. Engine model layout .

\section{RESULTS AND DISCUSSION}

The investigated marine DF engine steady state operation at both diesel and dual fuel modes was examined by performing simulation runs in a load range from $25 \%$ to $100 \%$ and constant engine speed at $514 \mathrm{rpm}$. A set of the derived results including cylinder maximum (peak) pressure, indicated and brake mean effective pressures, brake specific energy consumption, brake efficiency, turbocharger shaft speed, compressor operating points, air-fuel ratio, maximum in cylinder temperature of burnt zone, airfuel equivalence ratio, specific NOx emissions and specific $\mathrm{CO}_{2}$ emissions is presented in Figure 2. The obtained pressure diagrams of the first engine cylinder when the engine operates at $100 \%$ load at diesel and DF modes are shown in Figure 2. The percentage errors between the measured and predicted parameters are reported in Table 2. 
From the plots presented in Figure 2 and the data given in Table 2, it is derived that the obtained accuracy was quite adequate (within the range of approximately $\pm 3 \%$ ). Therefore it can be concluded that the developed model can be used to sufficiently represent the engine steady state behaviour.

Table 2. Percentage error between the measured and the predicted values.

\begin{tabular}{cllll}
\hline \multicolumn{5}{c}{ Diesel mode } \\
\hline Load (\%MCR) & $\mathrm{P}_{\mathrm{b}}$ & $\mathrm{p}_{\max }$ & $\mathrm{T} / \mathrm{C}$ speed & Eff. \\
\hline $100 \%$ & 2.60 & 0.16 & 0.04 & -3.11 \\
$85 \%$ & 2.36 & -0.60 & -0.02 & -2.90 \\
$75 \%$ & 1.88 & 0.19 & -0.06 & -2.43 \\
$50 \%$ & 1.14 & 0.42 & -0.79 & -1.64 \\
$25 \%$ & 1.22 & 1.77 & 0.02 & -2.22 \\
\hline \multicolumn{5}{c}{ Dual fuel mode } \\
\hline Load (\%MCR) & $\mathrm{P}_{\mathrm{b}}$ & $\mathrm{p}_{\max }$ & $\mathrm{T} / \mathrm{C}$ speed & Eff. \\
\hline 100 & -0.42 & 0.37 & 0.75 & 2.49 \\
85 & -1.15 & 0.33 & -0.32 & 3.43 \\
75 & -0.41 & 0.51 & -0.90 & 2.32 \\
25 & 1.70 & 0.42 & -0.27 & -1.16 \\
& 1.34 & 0.60 & 1.14 & -0.90 \\
\hline
\end{tabular}

MCR: maximum continuous rating; $\mathrm{P}_{\mathrm{b}}$ : brake power; $\mathrm{p}_{\max }$ : maximum cylinder pressure; $\mathrm{T} / \mathrm{C}$ : turbocharger; Eff: brake efficiency.

Table 3. Combustion model parameters for $100 \%$ load.

\begin{tabular}{lllcc}
\hline \multicolumn{5}{c}{ Diesel mode } \\
\hline Fuel & $\mathrm{m}$ & $\Delta \theta$ & SOC & Fraction \\
\hline MDO & 1.25 & 56 & -3.0 & 1 \\
\hline \multicolumn{5}{c}{ Dual fuel mode } \\
\hline Fuel & $\mathrm{m}$ & $\Delta \theta$ & SOC & Fraction \\
\hline Pilot MDO & 1.5 & 15.3 & -16.7 & 0.02 \\
Methane & 3.0 & 56.3 & -16.7 & 0.98 \\
\hline
\end{tabular}

Wiebe parameter a equals to 6.9 for all curves; m: Wiebe function exponent; $\Delta \theta$ : combustion duration (deg CA); SOC: start of combustion.

The combustion models parameters values (as used in equations (1) and (2)) calibrated to simulate the diesel and DF modes at $100 \%$ load are summarised in Table 3. By considering the derived pressure diagrams for $100 \%$ load (Figure 3), it can be inferred that the diesel mode combustion starts closer to the cylinder top dead centre (TDC), whereas in the case of DF mode the pilot injection and combustion starts earlier to avoid knocking problems. The dual fuel operation also results in a longer ignition delay due to presence of natural gas in the combustion chamber as it is also reported in Liu \& Karim (1997). The peak heat release rate of dual-fuel combustion is slightly higher and main combustion duration is shorter than the respective ones of the diesel mode. However, lower maximum pressure level is observed in the case of the DF mode, which is attributed to the engine turbocharger operation at lower speed due to the waste gate valve opening. As the boost pressure is lower in the case of the DF mode, the cylinder pressure during the compression process is also lower; however due to the advanced start of combustion and the shorter combustion duration, the lower maximum pressure and the resultant lower friction, the engine brake power is retained at the same level as in the diesel mode.

Therefore, in terms of the engine power output and mean effective pressures behaviour, it can be observed that similar values were obtained in each operating mode; the indicated mean effective pressure of the diesel mode seems to be only slightly greater, however the brake mean effective pressures in both modes are exactly the same as the difference is compensated by the slightly higher friction mean effective pressure (due to the greater maximum pressure of the diesel mode).

In terms of the equivalence air-fuel ratio $(\lambda)$, it is observed that in the DF mode the engine operates within a narrow $\lambda$ window with values between 2.1 and 2.3 (2.3 was observed at the low loads whilst 2.1 was obtained at medium and high loads). For the diesel mode, the obtained values for $\lambda$ are slightly higher (in the range from 2.5 to 2.9), which means that more air passes through the engine cylinders in the latter case. For the DF operation, the waste gate opening affects (actually reduces) the turbocharger speed, which in turn controls the boost pressure and as a result, the engine air flow and $\lambda$.

As it can be seen in Figure 2 (compressor map, turbocharger speed plots), the turbocharger speed, pressure ratio and flow rate is considerably reduced in the DF mode when the engine operates at high loads. Smaller reductions can be observed at the lower loads (25\%and 50\%). This denotes that the turbocharger matching needs special attention for a DF engine compared to the respective process for diesel or gas engines, as in the former case the requirements for two discrete modes need to be satisfied. Especially for the compressor selection, a number of parameters (usually contradictory) have to be considered including targeting operation in the high efficiency area and providing adequate margins to avoid compressor surging and turbocharger overspeed.

In terms of the engine efficiency at the two operating modes, it can be observed that the DF mode is more efficient at the high loads region obtaining values up to $47 \%$ at $100 \%$ load. When operating in the diesel mode, the engine obtains its highest efficiency at $75 \%$ load, whereas the engine efficiency only slightly changes in the load region from $70 \%$ to $100 \%$. For the DF mode, the efficiency decreases at a steeper gradient as the load decreases reaching its lowest value at $25 \%$ load; the engine obtains much higher efficiency at $25 \%$ load when operating at the diesel mode. 


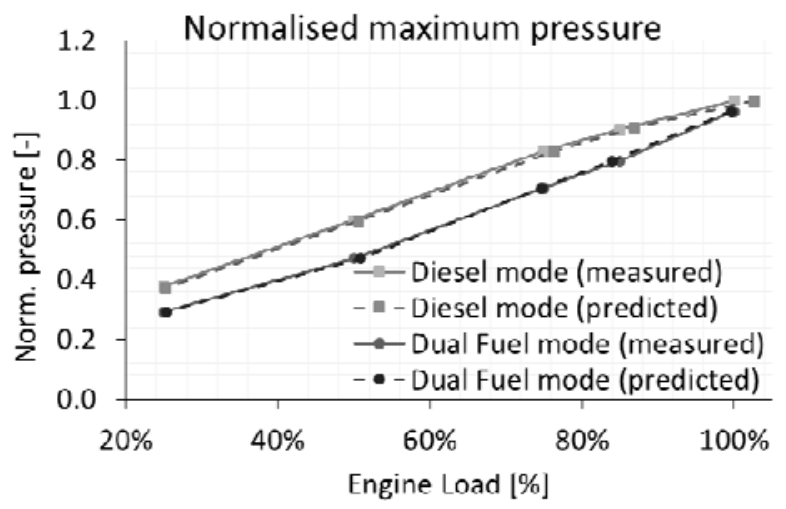

24
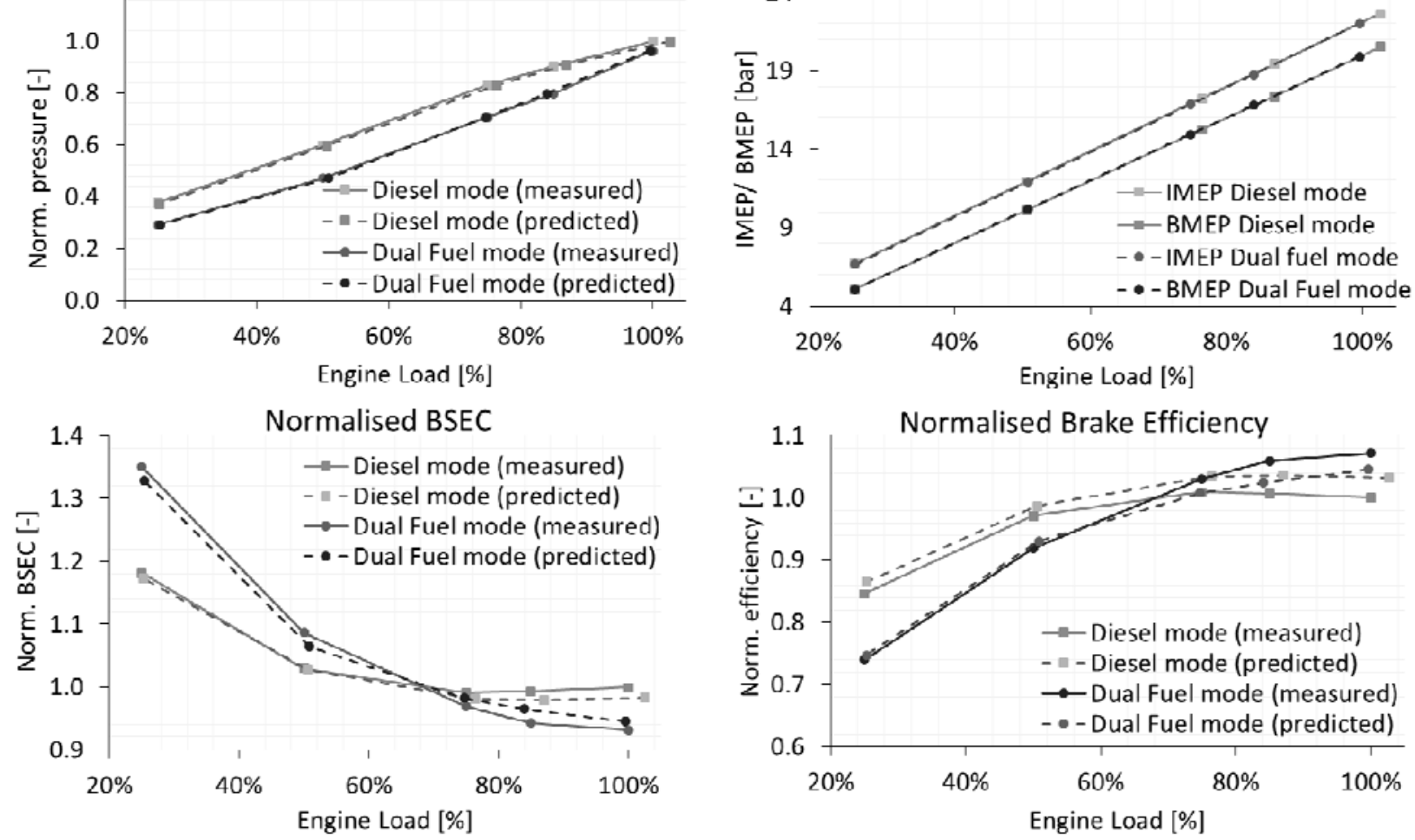

Normalised T/C speed
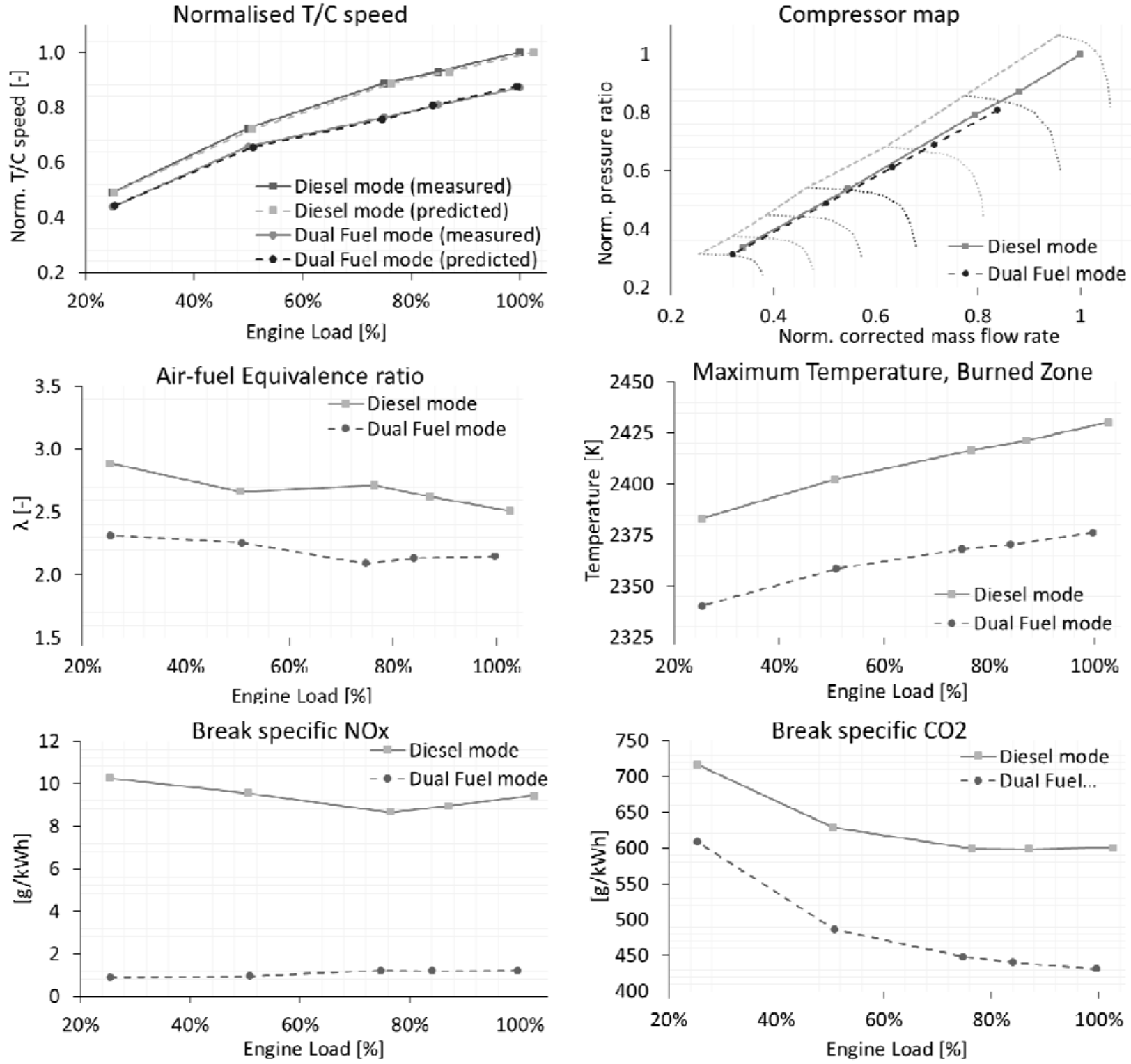

Figure 2. Simulation results and comparison with available experimental data. 


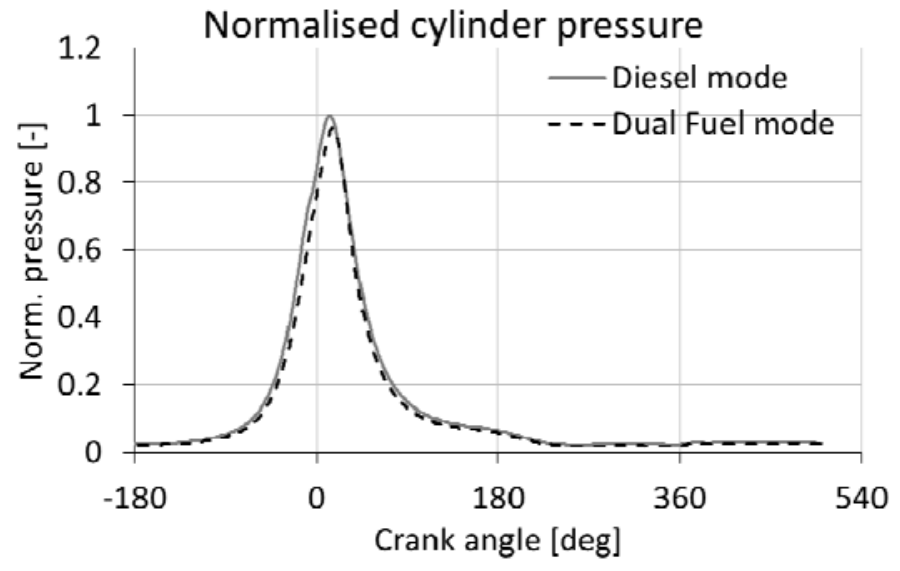

Figure 3. Pressure diagrams for diesel and dual fuel operation at MCR point.

This is attributed to the specific characteristics of diesel and DF operating modes as well as to the opening of the waste gate valve that results in lower turbocharger speed and pressure levels for the DF mode. Similar conclusions can be derived by analysing the brake specific energy consumption, which is the reciprocal of engine brake efficiency. The energy provided by the pilot diesel fuel accounts for $0.3 \%$ to $2.3 \%$ of the totally supplied fuel energy (the values increase with decreasing load).

Considering the calculated NOx and $\mathrm{CO}_{2}$ emissions, the following remarks can be noted. The specific NOx emissions are lower for the case of DF mode operation. It must be noted that for calculating NOx emissions, a two-zone model was used, which was calibrated only for $100 \%$ load operation at diesel mode. Then the model was used to predict the NOx emissions at the other investigated loads and operating modes. The NOx emissions for the diesel mode comply with Tier II limits, whereas the Tier III limit requirements are satisfied for the DF mode. In addition, higher values of the specific NOx emissions are obtained as the load reduces, which is also reported in Heywood (1998).

The NOx differences between the engine operating modes can be explained by considering the incylinder burnt zone temperature plots. As it can be observed from Figure 2, the maximum temperature values of the burnt zone for the diesel mode are higher than the respective values obtained for the DF mode. In average, a reduction of $85 \%$ in NOx emissions is obtained when changing the operating mode from diesel to DF.

The $\mathrm{CO}_{2}$ emissions of the DF mode are also reduced (25\% in average) due to the lower carbon to hydrogen ratio of the natural gas compared to the respective one of diesel fuel. Larger reduction is obtained at high loads region where the efficiency difference between the DF mode and diesel mode is greater. In summary, it can be concluded that the engine environmental impact is much lower when the engine operates at the DF mode.

\section{CONCLUSIONS}

In the present study, a marine four-stroke dual fuel engine was investigated by using GT-Power software in both diesel and DF mode operation. To set up the DF operating mode, two injector elements were used per engine cylinder; one for injecting the natural gas upstream each cylinder intake valves and one for injecting the pilot diesel fuel into each cylinder.

The main findings of the conducted research are summarised as follows:

- The developed model can predict with adequate accuracy the engine performance and emissions parameters both for the diesel and DF operation.

- The engine in the DF mode operates with almost constant air/fuel equivalence ratio in a narrow window from 2.1 to 2.3 , whereas slightly higher values of the air-fuel equivalence ratio are used for the diesel mode corresponding to greater air flow rates. This is obtained by controlling waste gate valve opening (for DF mode) to adjust the engine air flow and therefore the air/fuel ratio. Special attention must be paid during the turbocharger matching process as there are different requirements in each operating mode including avoidance of turbocharger overspeeds, providing an adequate compressor surge margin and operating the compressor within its high efficiency area.

- In the DF mode, the engine operates at lower receivers and in-cylinder pressure level. However, the mean effective pressure and power output is kept at the diesel mode levels due to the shorter combustion duration and the earlier start of combustion.

- The DF mode is more efficient than diesel mode at the high load region; however less efficient operation was observed at the lower load region.

- The $\mathrm{CO}_{2}$ emissions in the DF mode reduced approximately $25 \%$ in average due to the natural gas low carbon to hydrogen ratio. Larger reduction is obtained when the engine operates at the high load region where the efficiency is greater than that of the diesel mode.

- The NOx emissions reduced by $85 \%$ in average in the DF mode compared with the diesel mode. The diesel mode complies with the Tier II limits, whereas Tier III limits are met when the engine operated in the DF mode.

In conclusion, it can be stated that the utilisation of natural gas, which can be stored and handled in liquefied phase (LNG) can provide an attractive and environmentally friendly alternative that should be considered and adopted in the future ship designs. The obtained results can be used as guidance during the design process of the dual fuel engines or when designing a vessel energy management system. 


$\begin{array}{ll}\text { 0D } & \text { zero-dimensional } \\ \text { 1D } & \text { one-dimensional } \\ \text { 3D } & \text { three-dimensional } \\ \text { b } & \text { fuel fraction } \\ \text { BMEP } & \text { Brake Mean Effective Pressure } \\ \text { BSFC } & \text { Brake Specific Fuel Consumption } \\ \text { BSEC } & \text { Brake Specific Energy Consumption } \\ \text { CA } & \text { crank angle } \\ \text { CO } & \text { Carbon Monoxide } \\ \text { CO } & \text { Carbon Dioxide } \\ \text { DF } & \text { Dual Fuel } \\ \text { ECA } & \text { Emission Control Area } \\ \text { ECU } & \text { Engine Control Unit } \\ \text { EEDI } & \text { Energy Efficiency Design Index } \\ \text { EEOI } & \text { Energy Efficiency Operational Indicator } \\ \text { h } & \text { combustion effective heat per fuel mass } \\ \text { HC } & \text { Hydrocarbons } \\ \text { HFO } & \text { Heavy Fuel Oil } \\ \text { IMO } & \text { International Maritime Organization } \\ \text { LNG } & \text { Liquefied Natural Gas } \\ \text { m } & \text { Vibe function shape factor } \\ \text { mf } & \text { injected fuel amount per cylinder and } \\ & \text { cycle } \\ \text { MARPOL } & \text { International Convention for the Preven- } \\ & \text { tion of Marine Pollution } \\ \text { MGO } & \text { Marine Gas Oil } \\ \text { NG } & \text { Natural Gas } \\ \text { NOx } & \text { Nitrogen Oxides } \\ \text { PM } & \text { Particular Matter } \\ \text { rpm } & \text { Revolutions per Minute } \\ \text { SEEMP } & \text { Ship Energy Efficiency Management } \\ \text { SOC } & \text { Plan } \\ \text { SOx } & \text { start of combustion } \\ \text { T/C } & \text { Sulphur Oxides } \\ \alpha & \text { turbocharger } \\ \Delta \theta & \text { Vibe function parameter } \\ \lambda & \text { combustion duration } \\ \tau & \text { norr-fuel equivalence ratio } \\ & \end{array}$

\section{AKNOWLEDGMENTS}

Part of this work is conducted in the framework of INCASS project, which is funded by the European Union's Seventh Framework Programme under grant agreement No. 605200. This publication reflects only the author's views and European Union is not liable for any use that may be made of the information contained herein.

\section{REFERENCES}

Baldi, F., Theotokatos, G., \& Andersson, K. (2015). Development of a combined mean value-zero dimensional model and application for a large marine four-stroke Diesel engine simulation. Applied Energy. 154; 402-415.

Benvenuto G., Campora U., \& Laviola M. (2013). Simulation Model of a Methane-Fuelled Four Stroke Marine Engine for Studies on Low Emission Propulsion Systems. IMAM 2013, 15th International Congress on Maritime Association of the Mediterranean, 14-17 October 2013. A Corugna, Spain.

Bows-Larkin, A. Mander, S. Gilbert, P. Traut, \& M. Walsh. (2014). High Seas, High Stakes, High Seas Final Report. Tyndall Centre for Climate Change Research.

EMSA. (2015). EMSA. Retrieved from emsa.europa.eu: emsa.europa.eu/main/air-pollution.html

EPA. (2015). EPA. Retrieved from EPA GOV.: www.epa.gov/otaq/marine.htm

Gamma Technologies. (2015). GT Reference Manual.

ABS. (2013). Ship Energy Efficiency Measures - Status and Guidance. Publication No. TX 05/13 500013015.

Heywood, J. B. (1998). Internal combustion engine fundamentals. Mc-Graw-Hill, Inc.

IMO. (2014a). MARPOL Annex VI, Regulation 13.

IMO. (2014b). MARPOL Annex VI, Regulation 14.

Karim, G.A. (2015). Dual-Fuel engines. CRC Press, Taylor \& Francis Group.

Liu Z, \& Karim G.A. (1997).Simulation of combustion processes in gas-fuelled diesel engines. Proceedings of the Institution of Mechanical Engineers, Part A: Journal of Power and Energy, 211(2):159-169/1997.

Livanos, G., Theotokatos, G., \& Pagonis, D. (2014). Technoeconomic investigation of alternative propulsion plants for ferries and roro ships. Energy Conversion and Management. 79; 640-651.

MAN Diesel \& Turbo. (2012). SFOC Optimization Methods for MAN B\&W Two-Stroke IMO Tier II Engines, MAN Diesel \& Turbo: Augsburg, Germany,; Publication no. 5510-0099-00ppr.

MAN Diesel \& Turbo. (2015). ME-GI Gas-ready Ship. Publication No. 5510-0176-00ppr, Aug 2015, Denmark.

Merker, G.P., Schwarz, C., Stiesch, G., \& Otto, F. (2006). Simulating Combustion. Spinger.

Ott M. (2015). X-DF low-pressure dual-fuel engine technology. WinGD low-speed engines, Licensees Conference, Interlaken, Switzerland.

Theotokatos, G., \& Tzelepis, V. (2015). A Computational study on the performance and emissions parameters mapping of a ship propulsion system. Proc. IMechE Part M: J. Eng. Mar. Environ. 229, 58-76.

Wärtsilä. (2012). Retrofit of Wärtsilä diesel engine.

Wärtsilä. (2014). Product Guide Wärtsilä 50DF - 1/2014. Vaasa: Wärtsilä.

Wärtsilä. (2015a). Improving engine fuel and operational efficiency. Wärtsilä services business white paper engine fuel and operational efficiency.

Wärtsilä. (2015b). Wärtsilä. Retrieved from http://www.wartsila.com/products/marine-oil-gas/enginesgenerating-sets/dual-fuel-engines/wartsila-50df

Woschni, G., (1967). A Universally Applicable Equation for the Instantaneous Heat Transfer Coefficient in the Internal Combustion Engine (Vol. 76). SAE Transactions.

Xu, S., Anderson, D., Singh, A., Hoffman, M., Prucka, R., \& Filipi., Z. (2014). Development of a Phenomenological Dual-Fuel Natural Gas Diesel Engine Simulation and Its Use for Analysis of Transient Operations. SAE Int. J. Engines. 7(4). 1665-1673. 